\title{
The Incidental Acquisition of English Nominal Structures by a Young EFL Learner under Comprehension-based Lessons
}

\author{
Muhlisin Rasuki (Corresponding author) \\ Fakultas Keguruan dan Ilmu Pendidikan, Universitas Muhammadiyah Jember \\ J1. Karimata No. 49 Jember, Jawa Timur, Indonesia \\ E-mail: muhlisinrasuki@gmail.com
}

Received: 17-11-2016

Accepted: 15-01-2017

Advance Access Published: April 2017

Published: 01-07-2017

doi:10.7575/aiac.ijalel.v.6n.4p.45

URL: http://dx.doi.org/10.7575/aiac.ijalel.v.6n.4p.45

The author would like to thank Lembaga Pengelola Dana Pendidikan (LPDP), Ministry of Finance, Republic of Indonesia, for their continual support throughout the process of the study.

\begin{abstract}
This paper reports incidental acquisition of English nominal structures by a young EFL learner under comprehensionbased lessons. The learner was exposed to a series of English sentences containing the target structures through listenand-do activities. These activities required that the learner select different items based on the instructions given by the researcher. The exposure took place between 40 and 60 minutes in total spread over 3 days. In the fourth day, the learner was asked to give instructions (in English) to the researcher to select particular items. The learner's task performance was then transcribed and analyzed using complexity and accuracy measures. The results indicated that comprehension-based lessons were effective in facilitating incidental acquisition the target structures for the learner.
\end{abstract}

Keywords: second/foreign language (L2) learning, L2 acquisition, young L2 learner, English as a foreign language (EFL), comprehension-based lessons, task-based instruction

\section{Introduction}

\subsection{Input and L2 acquisition}

It is generally agreed that 'input' plays a central role in promoting second/foreign language (L2) acquisition. As Gass (1997, p. 1) put it, "no model of [L2] acquisition does not avail itself of input in trying to explain how learners create [L2] grammars". Input may be defined as L2-related data that learners receive both in and outside of the classroom (Leow, 2007, p. 21). Stemming from this premise, the present study aimed at investigating whether or not the provision of input alone (i.e., without necessarily requiring the learner to produce output) facilitated incidental acquisition of particular structures in the L2 in a way that promoted both receptive and productive skills.

\subsection{Theoretical review}

Krashen $(1981,1982,1985,1998)$ is among the most frequently cited authors in this area of research. His idea of Input Hypothesis has been very influential. Krashen (1981) distinguished between 'acquisition' and 'learning'. Whereas the former refers to the state whereby the learner "knows" L2 systems by means of subconscious learning, the latter refers to the state whereby the learner "knows" L2 systems by means of conscious learning. According to Krashen (1981, 1982), only acquisition allows the learner to use an L2 fluently and accurately in spontaneous speech, whereas learning only contributes to 'monitoring' L2 performance. Further, Krashen $(1985,1998)$ also noted that acquisition takes place only through exposure to 'comprehensible input'.

Although Krashen's Input Hypothesis has been challenged (e.g., Swain \& Lapkin, 1995), his point that exposure to comprehensible input constitutes a necessary condition to facilitate L2 acquisition remains valid. A study conducted by Shintani and Ellis (2010), for instance, shows that exposure to comprehensible input is important for L2 acquisition, especially by young L2 learners at a total beginner level. Unlike Krashen $(1985,1995)$, however, who perceived that comprehensible input is obtained primarily through pre-modified input conditions, Shintani and Ellis's (2010) study shows that interaction helps espouse the comprehensibility of the input in a way that promotes L2 acquisition. This finding lends support to Long's (1983) Interaction Hypothesis in that interactionally modified input is more beneficial for L2 learners than pre-modified input condition. Indeed, a series of studies comparing the effects of these two types of input condition (interactionally modified vs. pre-modified) show that the former is more effective than the latter in promoting L2 comprehension on the part of the learner (e.g., Gass \& Varonis, 1994; Loschky, 1994; Ellis, Tanaka \& Yamazaki, 1994). Further, all these studies also show that the use of 'tasks' (R. Ellis, 2003, 2009) can create the condition where the learner can get exposed to interactionally modified input, which is necessary for their L2 comprehension and acquisition. 
Although studies on task-based instruction have long predominantly focused on investigating the effectiveness of output-based tasks operationalized through production-based lessons, a growing number of studies appearing recently began to examine the effects of input-based tasks operationalized through comprehension-based lessons on L2 acquisition, most notably with young L2 learners (see Shintani, 2016). These latter studies show that comprehensionbased lessons are effective in promoting incidental acquisition of lexical items and morphological features in the L2 (e.g., Shintani \& Ellis, 2010; Shintani, 2012a). However, there is still a dearth of studies which examine the efficacy of input-based tasks (comprehension-based lessons) on incidental acquisition of L2 nominal structures by young L2 learners. The present study constitutes a preliminary attempt to investigate this issue. It focused on examining the efficacy of comprehension-based lessons operationalized based on the principles of task-based instruction (Ellis, 2003, 2009) on incidental acquisition of nominal structures in English by a young EFL (English as a foreign language) learner. In so doing, the study sought to reveal if such instruction allows the learner to acquire L2 structures that are typical of a natural speech. That is, although previous studies show that the type of instruction promoted incidental acquisition of lexical items and morphological features in the L2 by young learners, the studies failed to show that the learners produced the target forms (i.e. lexical items and morphological features) in a stream of speech. Rather, what the learners produced was mostly fragmented words containing the target L2 features (e.g., Shintani \& Ellis, 2010; Shintani, 2012a, 2012b). As such, the present study aimed to seek further empirical evidence regarding Ellis's (2009) claim that input-based tasks operationalized through comprehension-based lessons can provide rich opportunities for the learner to acquire 'new linguistic materials' that many critics of task-based instruction failed to acknowledge (see also Ellis, 2016; Shintani, 2012a).

Following Shintani and Ellis (2010) and Shintani (2012a, 2012b), the present study also employed listen-and-do activities where the learner was asked to listen to a series of instructions to select correct items out of many possible distractors.

\subsection{Research question}

In particular, the present study aimed to seek answer to the following questions:

1. Does the use of input-based tasks operationalized through comprehension-based lessons promote incidental acquisition of English nominal structures by a young EFL learner?

2. If so, what are the key features arising from the use of such tasks that facilitate the learner's acquisition of the target structures?

\section{Methodology}

\subsection{Design}

The present study is a case study aiming at investigating incidental acquisition of English nominal structures by a young EFL learner under an input-based task instruction. This type of instruction was operationalized through comprehensionbased lessons in which the learner was asked to perform 'listen-and-do activities' (Shintani \& Ellis, 2010). These activities lasted between 40 and 60 minutes in total spread over three days. During these three-day lessons, the learner was first informed (in Indonesian) that she would play a game with the researcher. The game would be conducted in English. The researcher would use English totally. The learner was allowed, but not required, to ask questions or request clarification whenever she failed to understand what the researcher said. This instruction was repeated in all three-day lessons.

\subsection{Participant}

The participant was a seven year old Indonesian female learner of L2 English. She is the daughter of the researcher. Before commencing the study, the learner's mother was informed about the procedures and purpose of the study and her consent was obtained thereafter.

At the time of the study, the learner was sitting in an Indonesian public primary school Grade One. The national curriculum in Indonesia excluded English as a subject in primary school. Even so, some primary schools chose to include English as an extracurricular activity where it aimed to introduce young learners to some English vocabularysuch as English words for fruits, colors and number - as well as to some formulaic expressions for daily greetingse.g., "good morning, how are you?, I am fine, thank you". Under no circumstances that the learner was taught to compose English sentences. In addition, even though the researcher (i.e., the learner's father) had years of experience living and studying in an English speaking country, the learner never had the same experience. In addition, the researcher hardly used English when communicating with the learner. As such, prior to commencing the study, the learner had neither prior knowledge of English words (except those for fruits, colors and number) nor did she have prior knowledge of English phrasal/sentence structures. That is to say, apart from English words for fruits, colors and numbers, all English words and structures that the learner produced after the treatments constitute the product of incidental acquisition.

\subsection{Materials}

The materials consisted of Lego items with different shapes and colors. There were 45 items altogether. These items were selected as they allowed the operationalization of "focused tasks" (see Ellis, 2003, 2009) where the researcher and learner needed to focus on the use of particular structures in order to be able to complete the tasks successfully (see also Loschky \& Bley-Vroman, 1993). 
The target structure was English nominal structures involving modifiers (number and adjective(s)) and a head-noun (e.g., 'one pink item', 'two small blue items', etc.). It is worth noting that these nominal structures are totally distinct from those in the learner's first language. The distinction is not only related to how modifiers and head-noun are sequenced, but also to how they are constructed. For instance, 'one pink item' will be translated in the learner's first language as 'satu benda berwarna merah muda (literally, '*one item color pink)', and 'two small blue items' will be translated into 'dua benda kecil berwarna biru (literally '*two item small color blue', i.e. no plural marker such as $/-S /$ is needed)'. Linguistically, therefore, English nominal structures might be considered very difficult for the learner to intentionally learn (cf. DeKeyser, 2005).

\subsection{Lessons}

The lessons comprised comprehension-based lessons operationalized through listen-and-do activities. These activities involved asking the learner to select correct items based on the commands and descriptions given by the researcher (cf. Shintani, 2012a, 2012b). The researcher is a native speaker of Indonesian with more than 8 years of experience teaching EFL to Indonesian learners. The researcher holds a master degree in TESOL from an Australian university and, at the time of the study, was doing a doctoral degree in applied linguistics in an Australian university.

The tasks (materials) used in the study followed the four criteria of tasks as proposed by Ellis (2003, 2009) in which tasks (1) focus on meaning of what is said rather than how something is said, (2) involve an information gap, (3) encourage the learner to use her own linguistic and non-linguistic resources to understand the meaning of what is said, and (4) involve a clearly defined communicative outcome.

\subsection{Test}

The test was given in the fourth day. It involved a free L2 production test where the learner, in return, was asked to tell the researcher to select correct items based on the descriptions she gave. The test constituted a free L2 production test because the learner was free to deploy her own L2 resources to communicate meaning to the researcher. There was no control over any linguistic structures that the learner used when doing the test. That is, the learner was simply told to tell the researcher in English which item(s) he needed to choose.

\subsection{Analysis}

Once the learner completed the test, her L2 production was then transcribed and analyzed. The transcription conventions follow Shintani and Ellis (2014, p. 542) (see Appendix 1), while the analysis employed an obligatory occasion analysis (R. Ellis \& Barkhuizen, 2005) and measures of complexity and accuracy as proposed by Lambert and Kormos (2014). In terms of complexity measures, Lambert and Kormos (2014) proposed differentiating the learner's use of the target structure on different levels of syntactic and semantic complexity. In terms of accuracy measures, Lambert and Kormos (2014) warned the researcher for his sense of "acceptability" when measuring grammatical accuracy. Lambert and Kormos's proposal was taken into account when measuring the complexity and accuracy of the learner's L2 production.

\section{Findings and discussion}

\subsection{Incidental acquisition of English nominal structures}

The first research question was whether the use of input-based tasks operationalized through comprehension-based lessons promote incidental acquisition of English nominal structures by a young EFL learner. In general, the findings show that it was the case. The learner was successfully able to use English nominal structures with a high degree of precision after receiving the instructional treatments. The qualitative analysis of the learner-researcher dyads arising in the free L2 production test also indicates strong evidence that the child used the target structures in the course of giving instructions to the researcher creatively and thus she successfully acquired nominal structures in English (see Extract 1). Recall that the learner had never engaged in oral interaction in English orally before, was not required to produce output when receiving instructional treatments. In addition, she also learned only a very small number of English words for fruits, number and color prior to receiving the instructional treatments.

Other English words that the learner used while completing the test included gradable adjectives (e.g., 'long' and 'small'), conjunction (e.g., 'and') and noun (e.g., 'item'). More importantly, how she combined these words into a grammatically correct order constitute the product of acquisition after receiving the instructional treatments.

Extract 1 (day 4, free L2 production test results, total duration 7 minutes 3 seconds)

1. $\mathrm{L} \quad:[[$ take] $]$ long pink item, two.

2. R : two ((takes the items)), okay.

3. L : four, four (.) yellow item.

4. R : hu'um ((takes the items), good.

5. $\mathrm{L}:(4.0)$ three green item.

6. $\mathrm{R} \quad$ : three green item $\underline{\mathrm{S}}$ ((recasts)), hu'um is it true? yea, okay.

7. $\mathrm{L}:$ (3.5) four small pink item.

8. R : OKAY. four small pink item $\underline{S}$ ((recasts))

9. L : $\operatorname{good}(($ laughs $))$.

10. R : good ((laughs), thank you. Ok. 
11. $\mathrm{L} \quad:(($ laughs $))$ two (6.0) two green item and one small blue item.

12. $\mathrm{R}$ : okay (.) two green items and one (.) [small blue item]

13. L : [small blue item].

14. $\mathrm{R} \quad$ : um 'um. ri::ght? ((gives the learner applause)) good (.) again.

15. $\mathrm{L} \quad:$ (4.0) four (.) four small pink item.

16. R : four small pink items ((recasts)), Ou! I was wrong ((laughs, accidentally picks five target items)), good, ok.

17. L : ((laughs)) papa tadi ngambil five (= papa just took five).

18. R : yea (.) my mistake.

19. L : two small pink item and one blue (.) one small blue item

20. R : two small pink items and one small blue item ((gives the learner applause)) right? ok.

21. L : Tak pilih kan (= I'll choose).

22. $\mathrm{R}:$ : u'um.

23. L : (4.0) three yello, three yellow item.

24. R : three yellow itemS ((recasts)). o::k. ri::ght.

25. L : (4.0) three, two,

26. $\mathrm{R} \quad$ : three or two?

27. L : ((inaudible, concentrates on looking at the items))

28. $\mathrm{R} \quad$ : u'um rows?

29. L : long pink item.

30. R : ok. so, two long pink items (.) okay, I have the last ones.

31. L : good. ((laughs))

32. R : good, ((laughs)) thank you.

33. L : sekarang tinggal green dan one (.) uh green dan yellow (= now only green and one (.) uh green and yellow left).

34. $\mathrm{R} \quad$ : green and yellow.

35. $\mathrm{L} \quad$ : four (.) four green item and two yellow item.

36. R : four green items and two yellow items. Fou::r ((picks up the items)) ok, a::nd two, ri::ght. ((applause)), ok, (.) $u:: m$ we have only one (.) yellow, but we have here two row and one row green items.

37. $\mathrm{L}:(2.0) *$ three one green one [[rwo]] item.

38. $\mathrm{R} \quad$ : u'um one row ((recasts))

39. L : one row item ((uptakes))

40. $\mathrm{R} \quad$ : three? three? ((clarification request))

41. L : two ((responds).)

42. $\mathrm{R} \quad:$ ha ((picks up the item))

43. L : good.

44. R : good ((applause)).

45. L : (2.0) four green item,

46. R : four green itemS ((recasts))

47. L : two

48. $\mathrm{R} \quad$ : two rows? with two rows?

49. L : iya (=yes).

50. R : four (.) I take all, now only these ones.

51. L : sekarang tinggal ini (= now only these left), five one row and one,

52. R : one yellow?

53. L : one yellow.

54. R : Ok. I take all. ((gives applause)) Thank you.

As can be seen from Extract 1, the learner successfully acquired English nominal structures consisting of modifiers (i.e., number and adjective(s)) and a head-noun (see, e.g., line 1, 3, 5, 7, 11, 15, 19, 23, 29, 35 and 45). Nonetheless, the learner failed to acquire plural marker $/-s /$. Such a failure might be caused by the redundancy in the input that the learner encountered during the treatments. Based on VanPatten's Input Processing Theory (e.g., VanPatten, 2002, 2015), the learner failed to process the meaning of the plural marker $/-S /$ because the meaning for 'plural' is embedded in the lexical items (e.g., two, three, four, etc.) (cf. Ellis, 1995). That is, the meaning of the English grammatical form for 'plural' was overridden by the lexical items which made it less salient to process (see also Kahneman, 1973, for a limited processing capacity theory). In fact, the researcher's repeated recasts did not help the learner notice the gaps in her utterances. The plural marker $/-s /$, however, did not constitute the target grammatical form of the present study. Shintani (2012a) and Shintani and Ellis (2010) provided a clear evidence of another implementation of comprehensionbased lessons (input-based task instruction) that is effective in facilitating young learners of L2 English acquire such a grammatical feature.

\subsection{Complexity and accuracy of the learner's L2 production}

Setting aside the issue of a failure in acquiring the plural form, the learner successfully showed her ability to use English nominal structures at different levels of complexity-e.g., "three green item (line 5), four small pink item (line 7), two green item and one small blue item (line 11). These instances indicate a creative use English nominal 
structures by the learner. Considering the complexity of "orderings" of these nominal structures and that such structures are also totally distinct from those in the learner's first language, it is remarkably interesting to find that the learner was able to use such structures with a high degree of precision after the treatments. These findings therefore provide further empirical evidence that comprehension-based lessons operationalized based on the principles of input-based tasks provide opportunities for the learner to acquire 'new linguistic material' (Ellis, 2009; see also Ellis, 1995).

Notwithstanding, the learner was less successful to acquire a more complex structure of nominal structures which include a prepositional phrase (e.g., *three one green one [[rwo]] item (line 37)). Previous instances from the researcher included, for instance, "take four green items with one row" or "two green items with two rows". However, this structure occurred infrequently in the researcher's utterances during the treatments and might have been insufficient for the learner to acquire such a complex nominal construction. As N. Ellis (2002) claimed, frequency plays an important role in acquisition. Nonetheless, despite her lack of acquired knowledge of such a complex construction, the learner voluntarily attempted to produce it in her production, albeit with little success (see also line 51 of Extract 1).

\subsection{Key features}

The second research question relates to the key features of the instructional condition that facilitates the learner's acquisition of English nominal structures. Of paramount important to note is that the learner's acquisition of such structures took place "incidentally" during the comprehension-based activities. Under no circumstances that the learner was asked to pay attention to how the language was used. That is, she was only asked to play a game with the researcher using English.

\subsubsection{Day 1}

At the outset, the learner faced difficulty to comprehend what the researcher said. Such difficulty, however, was expected and thus the researcher often used gestures and slowed down his speech to help the learner comprehend what he said. In that case, the researcher intentionally attempted to facilitate the learner's comprehension in order that she could choose correct target items (see Extract 2). This provision of assistance resembles Shintani's (2012a, 2012b) in that it aimed to scaffold the learner's comprehension and thus maintained her engagement in the lesson.

Extract 2 (day 1)

1. $\mathrm{R} \quad$ : please take (.) one long pink item.

2. $\mathrm{L} \quad:(($ no response $))$

3. $\mathrm{R} \quad$ : take one lo::ng ((gestures of 'long' with hands)) pink item.

4. L : (4.0) ini (=this one) ((takes a wrong item)).

5. R : no no ((waves with his hand)). That ((points toward the item)) is sma::1l ((gesture of 'small' with hands)). You need to take, one lo::ng ((gestures)) pink item, lo::ng ((gestures)).

6. L : (4.0) ini-ini (=this one, this one.) ((take a correct item)).

7. R : good, very good.

In this first-day treatment, the learner was exposed to English nominal structures consisting of modifiers (number and adjective(s)) and a head-noun. There were 32 instances of such constructions altogether. This first treatment took place within 18 minutes 43 seconds.

\subsubsection{Day 2}

In the next lesson, the learner was again introduced to the same structures. Different from those in the first lesson, however, some instances included two nominal structures joined by the word 'and'. Some instances even included a prepositional phrase (see Extract 3). As stated above, the learner was eventually successful in acquiring the first structures, although she failed to acquire the latter. In this second lesson, there was an indication that the learner's comprehension improved markedly. There were 24 instances (17 were "simple" and 7 were "compound" constructions of the target structures). In addition, there were also 2 instances of "complex" nominal structures involving a prepositional phrase. This second treatment was completed within 11 minutes and 38 seconds.

Extract 3 (day 2)

1. R : now take (.) one yellow item an::d two small ((gestures)) pink items.

2. L :apa? (=lit. what?)

3. R : one yellow item (1.0) an::d two, small pink items.

4. L : 3.0 ((pick up the correct items and show them to the researcher))

5. R : very good ((gives applause)).

6. R : now take two green items with one row.

7. L : ((no response))

8. $\mathrm{R} \quad$ : ((takes an item with one row and another item with two rows)) this is one row, these are two rows, this is one row, these are (.) two rows, okay? ((put the items back and resumes the game)).

\subsubsection{Day 3}

In the last treatment, the learner showed a significant increase in her comprehension skills. Neither gestures nor slow L2 speech production was needed to scaffold the learner's comprehension (cf. Shintani, 2012b). The learner also 
responded very quickly to the commands and descriptions given by the researcher (see Extract 4). This last instruction was completed within 4 minutes 33 seconds.

Extract 4 (day 3)

1. R. : one blue items an::d (.) two green items.

2. L : ((picks up the correct items and show them to the researcher))

3. $\mathrm{R} \quad$ : very good, and now $u: h$ you take, four small pink items.

4. L : ((picks up the correct items and show them to the researcher))

5. R : Okay, very good, and now you take two yellow items and o::ne lo::ng pink item.

6. L : ((picks up the correct items and show them to the researcher))

7. R : very good, and then now you take three, green items.

8. L : ((picks up the correct items and show them to the researcher))

9. R : very good, And now you take (.) uhum one blue item an::d, and two yellow items.

10. L : ((picks up the correct items and show them to the researcher))

11. R : very good.

There are, at least, two possible explanations of the learner's significant increase in her L2 comprehension skills during these three-day treatments. First, she was repeatedly exposed to the same words and syntactic structures in meaningful linguistic contexts (cf. N. Ellis, 2002). Such a repeated exposure was possible through repetition of the same tasks over three days. However, it is worth noting that such exposure is different from rote-repetition and structure-pattern drills in that there were no pre-determined L2 utterances and that all utterances arose from the researcher and learner's intention to communicate meaning. In contrast, the aim of rote-repetition and structure-pattern drills is predominantly to learn linguistic forms rather than to communicate meaning. The present study therefore provides additional evidence that task repetition is beneficial for the learner's L2 development (Bygate, 2001; Shintani, 2012b; Lambert, et al., 2016; see also Lambert (2016) for maintaining integrity in repeating tasks).

Secondly, the number of which the tasks were repeated (i.e., three times) might also contribute to the marked increase in the learner's L2 comprehension skills. Lambert, et al.'s (2016) study on 6-time task repetition with learners at different proficiency levels show that the learners' L2 performance improved significantly only in the first three performances.

\section{Conclusion}

The present study constitutes a preliminary attempt to investigate the efficacy of input-based tasks on incidental acquisition of L2 structures by a young L2 learner. As a preliminary attempt, the conclusion is also tentative. It is unlikely to generalize the findings of the present study to the general populations of young L2 learners. Further (replication) studies involving a much larger group of young L2 learners from different linguistic backgrounds in different instructional contexts need to be conducted. As regards the results of the present study, however, it is found that comprehension-based lessons operationalized based on the principles of input-based task instruction conducted three times were effective in facilitating the acquisition of quite complex L2 structures. Process features arising from the use of the tasks included, among others, (1) authentic use of target structures in the course of communicating meaning, (2) repeated exposure to the target structures in meaningful linguistic contexts, and (3) interactionally modified input as a means to facilitate the learner's L2 comprehension. All these features are indispensable in the course of L2 acquisition.

\section{References}

Bygate, M. (2001). Effects of task repetition on the structure and control of oral language. In M. Bygate, P. Skehan \& M. Swain (Eds.), Researching pedagogic tasks: Second language learning, teaching and testing (pp. 23-48). Harlow: Longman.

DeKeyser, R. (2005). What makes learning second-language grammar difficult? A review of issues. Language learning, 55(S1), 1-25. doi: 10.1111/j.0023-8333.2005.00294.x

Ellis, N. (2002). Frequency effects in language processing. Studies in second language acquisition, 24(02), 143-188. doi: https://doi.org/10.1017/S0272263102002024

Ellis, R. (1995). Interpretation tasks for grammar teaching. TESOL Quarterly, 29(1), 87-105. doi: $10.2307 / 3587806$

Ellis, R. (2003). Task-based language learning and teaching. Oxford: Oxford University Press.

Ellis, R. (2009). Task-based language teaching: Sorting out the misunderstanding. International Journal of Applied Linguistics, 19(3), 221-246. doi: 10.1111/j.1473-4192.2009.00231.x

Ellis, R. (2016). Aunt Sallies and real issues: Moving task-based language teaching forward. Taking it to task, 1(1), 3-8. Ellis, R. \& Barkhuizen, G. (2005). Analysing learner language. Oxford: Oxford University Press.

Ellis, R., Tanaka, Y., \& Yamazaki, A. (1994). Classroom interaction, comprehension, and the acquisition of L2 word meanings. Language learning, 44(3), 449-491. doi: 10.1111/j.1467-1770.1994.tb01114.x

Gass, S. (1997). Input and interaction in second language acquisition. Mahwah, NJ: Erlbaum.

Gass, S. \& Varonis, E. (1994). Input, interaction, and second language production. Studies in second language acquisition, 16(3), 283-302. doi: https://doi.org/10.1017/S0272263100013097 
Kahneman, D. (1973). Attention and effort. Englewood Cliffs, NJ: Prentice-Hall.

Krashen, S. (1981). Second language acquisition and second language learning. Oxford: Pegamon.

Krashen, S. (1982). Principles and practice in second language acquisition. Oxford: Pegamon.

Krashen, S. (1985). The input hypothesis: Issues and implications. London: Longman.

Krashen, S. (1998). Comprehensible output?. System, 26(2), 175-182. doi: 10.1016/S0346-251X(98)00002-5

Leow, R. (2007). Input in the L2 classroom: An attentional perspective on receptive practice. In R. DeKeyser (Ed.), Practice in a second language: Perspectives from Applied Linguistics and Cognitive Psychology (pp. 21-50). New York, NY: Cambridge University Press.

Loschky, L. \& Bley-Vroman, R. (1993). Grammar and task-based methodology. In G. Crooks \& S. Gass (Eds.), Tasks and language learning: Integrating theory and practice (pp. 123-167). Clevedon, UK: Mulitilingual Matters.

Loschky, L. (1994). Comprehensible input and second language acquisition. Studies in Second Language Acquisition, 16(3), 303-323. doi: https://doi.org/10.1017/S0272263100013103

Long, M. (1983). Native speaker/non-native speaker conversation and the negotiation of comprehensible input. Applied Linguistics, 4(2), 126-141. doi: 10.1093/applin/4.2.126

Lambert, C. (2016). Task integrity and task frequency in the L2 classroom. Taking it to task, 1(1), 9-16.

Lambert, C., \& Kormos, J. (2014). Complexity, Accuracy, and Fluency in Task-based L2 Research: Toward More Developmentally Based Measures of Second Language Acquisition. Applied Linguistics, 35(5), 607-614. doi: 10.1093/applin/amu047

Lambert, C., Kormos, J. \& Minn, D. (2016). Task repetition and second language speech processing. Studies in second language acquisition, FirstView, 1-30. doi: http://dx.doi.org/10.1017/S0272263116000085

Shintani, N. (2012a). Input-based tasks and the acquisition of vocabulary and grammar: A process-product study. Language Teaching Research, 16(2), 253-279. doi: 10.1177/1362168811431378

Shintani, N. (2012b). Repeating input-based tasks with young beginner learners. RELC Journal, 43(1), 39-51. doi: $10.1177 / 0033688212439322$

Shintani, N. (2016). Input-based Tasks in Foreign Language Instruction for Young Learners. Amsterdam: John Benjamins.

Shintani, N. \& Ellis, R. (2010). The incidental acquisition of English plural $-s$ by Japanese children in comprehensionbased and production-based lessons: A process-product study. Studies in second language acquisition, 32(4), 607-637. Doi: https://doi.org/10.1017/S0272263110000288

Shintani, N., \& Ellis, R. (2014). Tracking 'learning behaviours' in the incidental acquisition of two dimensional adjectives by Japanese beginner learners of L2 English. Language Teaching Research, 18(4), 521-542. doi: $10.1177 / 1362168813519885$

Swain, M., \& Lapkin, S. (1995). Problems in output and the cognitive processes they generate: A step towards second language learning. Applied linguistics, 16(3), 371-391. doi: 10.1093/applin/16.3.371

VanPatten, B. (2002). Processing instruction: An update. Language learning, 52(4), 755-803. doi: 10.1111/14679922.00203

VanPatten, B. (2015). Input processing in adult SLA. In B. VanPatten \& J. Williams (Eds). Theories in second language acquisition: An introduction (pp. 113-134). New York, NY: Routledge.

Appendix 1. Transcription conventions

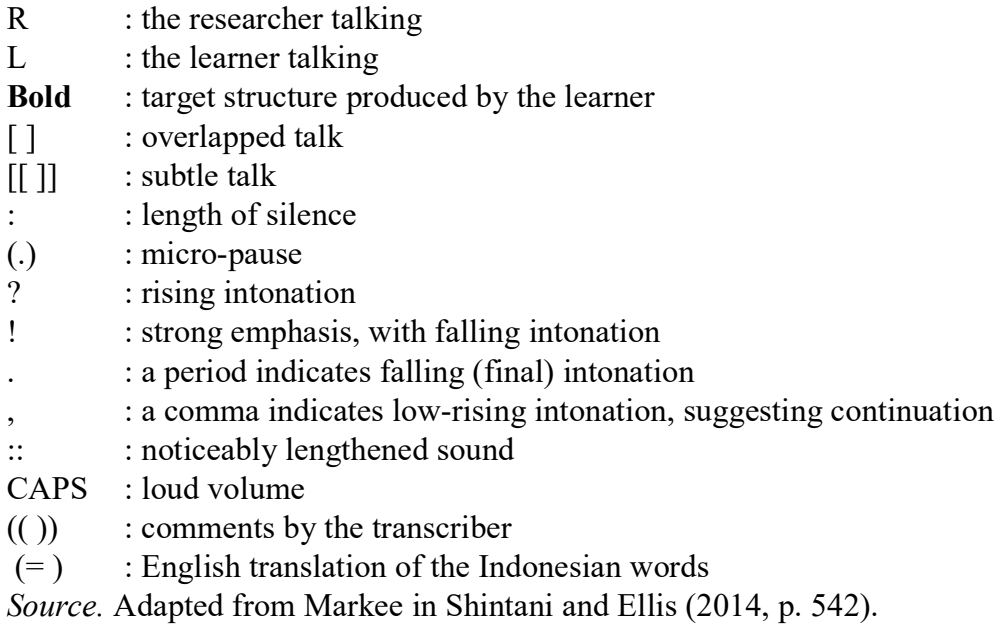

